Published in final edited form as:

J Marriage Fam. 2011 August ; 73(4): 832-844.

\title{
Headed towards Equality? Housework Change in Comparative Perspective
}

\author{
Claudia Geist and \\ University of Utah, Department of Sociology, 380 S 1530 E, Rm 301, Salt Lake City, UT 84112 \\ Philip N. Cohen \\ University of North Carolina at Chapel Hill, Department of Sociology, 155 Hamilton Hall CB\#3210, \\ Chapel Hill, NC 27599-3210
}

\section{Abstract}

This paper examined gendered housework in the larger context of comparative social change, asking specifically whether cross-national differences in domestic labor patterns converge over time. Our analysis of data from 13 countries $(N=11,065)$ from the 1994 and 2002 International Social Survey Program (ISSP), confirmed that social context matters in shaping couples' division of labor at home, but also showed that context affects patterns of change. Our results suggested that, compared to the most egalitarian countries, the shift in housework patterns was greatest among the most traditional countries. This provides support for the thesis of cultural convergence, but the evidence did not suggest that such convergence will lead to complete equality in the foreseeable future.

\section{Keywords}

Housework/Division of Labor; Social Context; Cross-National; Social Trends/Social Change; Fairness and Equality

Compared with trends in other aspects of social life, change in the domestic division of labor has been slow, and traditional patterns remain prevalent. Nevertheless, there is a broad trend toward more gender equality in housework and a decline in the burden shouldered by women. A blossoming body of research has examined the housework division of labor in comparative perspective (Alwin, Braun, \& Scott, 1992, Batalova \& Cohen, 2002, Coltrane, 2000, Fuwa \& Cohen, 2007, Geist, 2005, Knudsen \& Waerness, 2008, Ruppanner, 2008, Treas \& Drobnic, 2010), but only a relatively small number of studies have combined a comparative perspective with multiple time points and a focus on change over time (Hook, 2010, Hook, 2006). Hook's work, based on cross-national time use data from over four decades, has greatly improved our understanding of the effect of national practices and policies on men's and women's housework in general and segregation of housework tasks in particular. Nevertheless, change in cross-national patterns, rather than within specific countries, remains a gap in our understanding of gendered housework and social change.

In this study we focused on one specific issue in comparative housework research, namely whether national patterns in the domestic division of labor are converging over time, following the logic of a world culture moving towards greater levels of gender equality (Inglehart \& Norris, 2003, Meyer, Boli, Thomas, \& Ramirez, 1997). Comparative studies of social change have served to deepen our understanding of the underlying forces at work in such diverse arenas as the relationship between democracy and economic inequality (Muller, 1988), intergenerational mobility (Ganzeboom, Treiman, \& Ultee, 1991), and cultural 
modernity (Schooler, 1996). We believe similar benefits would be accrued from the study of comparative change in the household division of labor.

Modernity and gender egalitarianism are sometimes seen as inextricably linked. On one extreme, some believe that, "[G]ender inequality does not fit the needs, the distribution of power, the organizational logic, or the moral perspectives of modern society" (Jackson, 1998). On the other hand, some feminists have found that modernity merely spawns "new manifestations of patriarchal structures and ideologies," because patriarchy is "the flesh and blood of modern, progressive capitalism" (Mies, 1998). Although we cannot hope to resolve this debate, studying change in comparative perspective is a crucial tool for addressing that larger question. Demonstrating that cross-national differences in the housework gender gap are narrowing over time, net of both couple and national level factors, would provide further evidence for a global trend towards "modern" gender patterns. On the other hand, if the gaps remain stable or even diverge, that would suggest an unstable relationship between gender inequality and social change - with no central egalitarian trend- and underscore the contested nature of progress toward gender equality.

The domestic division of labor is a socially embedded process, and change in housework patterns is linked to larger-scale processes. The comparative work to date has shown that context matters for family and housework: Societal standards cannot be ignored when trying to understand couple's housework patterns. Using data from 13 countries from the 1994 and 2002 International Social Survey Program (ISSP), we sought to address whether and how patterns in the division of labor converge towards equality.

\section{Micro Level Research on Housework}

An impressive body of literature has established the continued importance of three distinct factors that shape the domestic division of labor: Relative resources affect power dynamics within couples, as resources provide advantages in housework bargaining (Brines, 1994, Sorensen \& McLanahan, 1987). Time availability is important because gender differences in paid work hours and schedules make women more likely to engage in domestic work (Bianchi, Milkie, Sayer, \& Robinson, 2000, Coltrane \& Ishii-Kuntz, 1992). And gender itself is an essential factor that shapes housework patterns. Beyond gendered resources and schedules, men and women "do" gender to reaffirm their identities through interaction, including in their performance of domestic labor (De Ruijter, Treas, \& Cohen, 2005, South \& Spitze, 1994, West \& Zimmerman, 1987). For an extensive review of these established factors see $\operatorname{Hook}(2010)$.

The household division of labor in the United States and elsewhere has become more equal over time, partly because men's housework time has increased, but more because women's housework time has decreased (Bianchi et al., 2000, Gershuny, 2000, Hook, 2006). Hook's $(2006,2010)$ studies in particular assessed variation across time using data from a variety of countries, and she concluded that the gap between men's and women's housework has narrowed across countries. It is not clear, however, how the mechanisms that shape housework have shifted over time.

\section{Cross-National Research and Macro Level Theories}

The cross-national variation in the domestic division of labor is systematic in nature. Overall, women's equality in the normative cultural, economic and political realm is associated with less housework time and more egalitarian patterns of housework sharing. Studies have shown that more egalitarian societies have more equal divisions of household labor. Fuwa (2004) specifically identified the importance of economic development, women's labor force participation and aggregate gender ideology, Geist (2005) found 
important differences across welfare state context, and Fuwa and Cohen (2007) identified the importance of labor market discriminatory practices and policies such as parental leave. Overall, there is extensive evidence for the importance of sociopolitical context for the domestic division of labor and other aspects of family life; Cooke and Baxter (2010) provide an excellent recent review of this field.

Increasing insights in how the national-level context shapes housework and the domestic division of labor have not been matched by a closer examination into whether the impact of policy arrangements and cultural norms on housework patterns change over time. This leaves open the question of whether international housework patterns are converging, or whether policy-based country differences remain stable over time. Perceptions of convergence in family patterns across societies have played a central role in modernization theories, whether driven by ideational or structural perspectives (Thornton, 2005). Although family sociologists - most prominent among them perhaps William Goode (1963) - have long treated industrialization and technological change as structural forces compelling societies toward common family patterns, careful research (including Goode's) also has emphasized the importance of ideological forces, which have the capacity to diffuse apart from (or ahead of) economic and technological development(Lesthaeghe, 1983). More recently, the theory of the second demographic transition posits an ideological "spread" of family-oriented norms around the world (Lesthaeghe, 2010). A consistent position of convergence theories is that change is more rapid in more "traditional" societies as innovations and interventions from leading societies diffuse - or apply pressure - to those that lag behind (Boli \& Thomas, 1997, Meyer et al., 1997).

One mechanism for convergence with regard to gender could be transnational networks, specifically the transnational feminist movement, which has an impact on national level policy (True \& Mintrom, 2001). As political pressure crosses national borders, movement networks transmit ideas and expectations (McAdam \& Rucht, 1993). Legal reforms and public policies also spread in ways that might enhance prospects for gender equality across countries simultaneously (Krook, 2008). The diffusion of gender equality, driven by political demands in addition to economic development (Moghadam, 2000), may apply pressure toward equality in the home.

Usually, change over time is most easily detectable when longer time spans are covered. We argue that in the time frame of our study, 1994 to 2002, substantial social change took place, especially when considering the broad spectrum of countries we consider. For example, "traditional" family norms weakened in a number of countries during this period (Gubernskaya, 2010), and there was a liberalizing of gender attitudes in the United States in particular during the 1990s (Bolzendahl \& Myers, 2004, Brooks \& Bolzendahl, 2004). In Eastern European countries, the era of state socialism ended in the early 1990s and since then their economic, political and social systems have experienced great changes, with many joining the European Union by 2004.

Our focus in this paper was on convergence and cross-national change. In that vein, we investigated two hypotheses. First, based on women's continuing integration into labor markets worldwide, and the move towards greater gender equality, we expected that the domestic division of labor has become more egalitarian, as shown in previous studies. It is not clear, however, whether trends toward equality lead to differences between couples growing less pronounced. If gender equality in housework is part of a broad cultural shift, then differences between couples with different characteristics should diminish. On the other hand, those very trends towards greater similarity in men's and women's characteristics may increase the bargaining power associated with women's labor force participation and 
strengthen the role of gender attitudes in shaping couples housework patterns. As a result, we tested competing hypotheses regarding micro-level convergence:

The effect of couple-level characteristics on the domestic division of labor diminishes over time. (Hla)

The effect of couple-level characteristics on the domestic division of labor increases over time. $(\mathrm{H} 1 \mathrm{~b})$

We also investigated convergence cross-nationally. Existing research has shown that the domestic division of labor is not merely a result of individual or couple level characteristics and negotiations. The embeddedness of couples in social context plays a role both in the level of housework performance and in the effects of couple characteristics (Cunningham, 2005, Davis \& Greenstein, 2004, Fuwa \& Cohen, 2007, Geist, 2009, Geist, 2010). This growing literature on comparative housework mostly compares housework across contexts cross-sectionally, so little is known about the differences in rates of change across contexts. We examined whether countries with a traditional domestic division of labor tend to "catch up." The cross-national convergence hypothesis is that:

Cross-national differences in the household division of labor converge, as countries with a more traditional division of labor experience greater changes towards equality than countries that were already more egalitarian. (H2)

The alternatives to the convergence hypothesis are constant change across countries, suggesting that all countries change along a similar pattern; or divergence, resulting in more rapid change among already egalitarian countries, and slower changes among more traditional countries.

\section{Method}

We relied on the 1994 and 2002 waves of the International Social Survey Program (International Social Survey Programme, 1994, International Social Survey Programme, 2002). The ISSP is a cross-national coordinated set of surveys; these particular modules focused on issues pertaining to family and gender issues (for a detailed description of the ISSP structure and origins refer to the ISSP website at www.ISSP.org and Smith (1992). We also used publicly available databases to obtain country-level measures, as described in the measurement section.

We examined the division of labor at home across three household tasks for 13 countries for both years (see Table 1). Only countries that participated in both waves and for which information on macro level indicates were available were included. We treated Northern Ireland as a separate country from Great Britain as it was surveyed separately. For the macro level variables both countries were assigned the values for the United Kingdom (except country level gender attitudes, which were computed from the 1994 ISSP, and length of parental leave). We restricted the sample to individuals who were married or had a steady partner. Because the partner's sex was not recorded, we had to assume all couples were man-woman pairs. We included only observations from those who lived in a household that had non-zero household income (from all sources), at least two adults and who were not enrolled in school. Because labor market status is a crucial factor in the study of housework, the sample was restricted to those in "prime" working age, 25 to 55. These restrictions reduced the sample to 15317 respondents. $4252(27.8 \%)$ respondents were excluded due to missing data. Income was the key source of missing data $(3048,19.9 \%)$, especially for households with one or more partner out of the labor force; 390 respondents had missing data on the outcome measure. Listwise deletion of missing data resulted in a sample of 11,065 observations. 


\section{Domestic Division of Labor}

The surveys included questions about the allocation of different household tasks. Respondents were asked to indicate "who in your household does the following things:" preparing dinner, doing laundry, and shopping for groceries. In this paper, we focused on the three tasks that are traditionally considered routine, daily tasks usually done by women, because they have to be done in almost all households. We excluded questions about responsibility for small repairs and taking care of sick relatives, as these tasks occur much less frequently, or not at all in some households. In 2002 respondents also were asked about cleaning responsibilities, but this item was not included in 1994). Similar measures have been widely used in comparative housework research (Fuwa, 2004, Geist, 2005, Knudsen \& Waerness, 2008, Stier \& Lewin-Epstein, 2007, Yodanis, 2005).

Respondents were asked to state whether it was "always" the respondent himself or herself, "usually" the respondent, "about equal/both together", "usually the spouse/partner", "always the spouse/partner", or whether the task is done "by a third person." Tasks done by a third person were considered to be shared equally.

For our analyses, a value of -2 was assigned if a task was done "almost always" by the woman, -1 was assigned if a task was "usually" done by the woman. Equal sharing and tasks being done by a third person were coded as 0 . If a man was "usually" or "almost always" responsible for a tasks values of 1 and 2 were assigned. Values for all three tasks were added, and in the resulting housework score, more negative values indicate more housework responsibility of the female partner. As such, the resulting housework scale represents a measure of degree of male relative housework responsibility $(-6=$ all tasks always/usually done by the female partner to $+6=$ all tasks always/usually done by the male partner).

\section{Couple Level: Independent Variables and Controls}

In the multivariate models, we included measures of established individual and couple-level predictors of the domestic division of labor. Relative resources were measured by the male partner's share of the household income. We allowed those who are not employed to have nonzero income because respondents may have reported earnings from employment that had just ended. Time availability was represented by two measures: Employment status of both partners and household size. We distinguished between full-time employment, part time employment, and not working for pay. The latter group is heterogeneous and includes both homemakers and those who are unemployed, yet it may also include respondents who work for a family business on an unpaid basis. In the multivariate models, full-time employed respondents with partners who work full time were the reference group. Household size was used as proxy for the housework burden; whereas additional measures for the number and ages of children would be desirable, they were not consistently available across years and countries.

To capture respondents' gender attitudes we created an additive score based on the responses to three well-established items concerning women and paid work: (1) "A man's job is to earn money; a woman's job is to look after the home and family," (2) "all in all, family life suffers when the woman has a full-time job," and (3) "a pre-school child suffers if his or her mother works." Respondents were asked to "strongly disagree" (assigned a value of 1), "disagree," "neither agree nor disagree," "agree," or "strongly disagree" (assigned a value of 5). Higher values indicated greater support for women's paid employment $(a=0.75)$ We further distinguished between those who are married to their partner and those who are not, because marriage has been shown to make traditional role expectations more salient and may also reflect a more traditional orientation of respondents, 
compared to those who are cohabiting (Batalova \& Cohen, 2002). Age and education indicators were only available for survey respondents. Although it would be preferable to have information on partners' gender attitudes, the attitudes of either partner can be expected to affect the couple's division of labor.

\section{Macro Level Measures}

Housework Context-One key contextual measure was the domestic division of labor at the country level. We computed the average housework score across all respondents in each country in 1994. As such this measure represents a country-level "standard" in the domestic division of labor.

Gender Attitudes and Family Structure-We included an aggregate measure of attitudes towards men's and women's separate spheres. We computed the mean response for each country for the statement "A man's job is to earn money; a woman's job is to look after the home and family," (see response options above), based on the 2002 data. Previous research has shown that higher national cohabitation rates are associated with a more egalitarian gender division of household labor (Batalova \& Cohen, 2002), perhaps because these couples set a more egalitarian standard (Davis, Greenstein, \& Gerteisen Marks, 2007). We included national cohabitation rates for individuals 20 years and older for 2000 and 2001, from the OECD family databank (2006 information for Australia and New Zealand, retrieved from http://www.oecd.org/dataoecd/52/27/41920080.pdf).

Gendered Labor Market Indicators-We included a number of measures of women's position in the labor market. Female labor force participation, from World Bank data, indicates the percentage of the female population ages 15 to 64 in the labor force. We also included the female-to-male ratio of estimated earned income for 2002, from the Human Development Report. We further included a measure developed by Fuwa and Cohen (2007) ( adapted from Chang, 2000) that indicated the absence of discriminatory employment policies. It reflected how many of three ILO anti-discrimination treaties are upheld in a given country, including: the prohibition of women working in a night shift, the prohibition of women working underground, and sex restrictions in heavy loads. The absence of discriminatory policy score ranged from 0 , when all three treaties are implemented, to 3 when none of the treaties were present.

Policy Context-We included two measures that reflect the situation of parents and the organization of childcare. These issues affect women more than men as women still bear the majority of parenthood responsibilities. As a result, policies on these issues may affect the gender balance in other spheres, including the domestic division of labor. We included a measure of the length of parental leave in weeks (based Fuwa \& Cohen 2007) and the estimate of public childcare availability for children three years to six years of age (part of a measure used by Fuwa \& Cohen 2007, provided to us by the authors).

We also relied on a welfare categorization that builds on Esping-Anderson (1990 EspingAnderson (1999). We distinguished between liberal welfare states (Australia, Great Britain, New Zealand, Northern Ireland, USA), conservative (Austria, Germany) and "Eastern" welfare states (Bulgaria, Czech Republic, Hungary, Poland, Slovenia). We only had one social democratic welfare state (Norway) so we could not distinguish between welfare state regime and country effects for this category. The main contrast examined was between Eastern and liberal welfare states, which is of particular interest given the continued marked differences between Eastern European and other European countries (Batalova \& Cohen, 2002). 


\section{Analytic Strategy}

Our analyses proceeded in two stages. In a first step, we described housework patterns in 1994 and 2002 across all countries, based on country averages. Then we conducted multivariate analyses that examined to what extent the variation across time and countries was due to variation in the sample composition. We used random intercept and random slope models (using the xtmixed command in Stata 11): We first estimated random intercept models that allowed us include variation in housework averages across countries, net of individual characteristics. We assessed Hypothesis 1 by allowing individual and couple level effects to vary across the years by adding interaction effects by survey year. We also estimated a random slope model that allowed the effect of time to vary across countries.

In our second analytic step we examined housework patterns in 2002 and include macrolevel characteristics in our random intercept models. We tested Hypothesis 2 by first examining the effect of the 1994 country level housework on couple 2002 housework responses. We also explored whether change over time was more pronounced in countries with a more traditional division of labor, by testing for curvilinearity (using both second and third order polynomials) in the effect of country level housework in 1994 on 2002 housework patterns. This provided a stringent test of Hypothesis 2, because it not only allowed for the possibility of the effect of context to be constant across the spectrum of aggregate housework sharing, but also allowed the effect of context to potentially be stronger among the more egalitarian countries.

Random intercept models allowed us to take into account the hierarchical nature of our data, and although the number of groups/clusters was small (13 countries), it was comparable to that of other studies using the same methodology (Alwin et al., 1992, Gesthuizen, Solga, \& Künster, Forthcoming, Lohmann, 2009). The main concern with having a small number of groups is that the estimates at the group level could be compromised, however, as our main focus was on the fixed effects this was not a central concern. Supplemental analyses using alternative methods (i.e. dummy variables for countries, or country-clustered robust standard errors) yielded substantively similar results and the models we present were typically more conservative in nature. Model fit is assessed using the Bayesian Information Criterion (BIC) and the reduction in between-country variation in the outcome.

\section{Results}

Figure 1 shows how housework patterns at the aggregate level have changed in the 13 study countries between 1994 and 2002 (recall that more negative scores indicate less male housework responsibilities). To compare the fit of observed data to our hypotheses, we included two lines in Figure 1. The dashed line indicates no change between the years, so for countries where observations are on or near this line there was no change in housework patterns between 1994 and 2002. The dotted line was fitted across the country averages; although individual countries showed deviations over the period, on average there has been very little change. Next we examined change over time net of sample characteristics by taking into account individual and couple characteristics.

As a baseline, we present a model that only included an indicator of survey year and allowed for between-country variation (Model 1). We see that there was only moderate variation across countries and that the average difference between the years was not significant. In Model 2 we included the established set of couple-level characteristics to test whether the similarity across the years remained. The lack of a net (main) effect of time on the housework patterns persisted, indicating that there is no change towards more egalitarian division of labor patterns between 1994 and 2002. 
The results from the fully interactive model (Model 3) were not in line with Hypothesis 1a that suggested that couple characteristics diminish over time, but instead provided limited support for Hypothesis 1b. Several effects became stronger (the main effects in question were negative, so a negative interaction effect indicated that the effect became stronger); The reporting gap between men and women deepened over time, and the difference between households where the female partner worked part time compared to full time was greater in 2002 than in 1994 (as was the difference between households with female full-time workers and those with female homemakers). In Model 3, we also included the time indicator as a random slope, to allow the change between the years to be different for each country. The results showed significant variation in the difference between 1994 and 2002 across countries. As this variation was net of changes in sample composition it suggested that larger scale factors play a role in determining couples' housework patterns.

We were particularly interested in whether the cross-national variation in patterns of change was systematic: the convergence hypothesis $(\mathrm{H} 2)$ predicted greater change towards equality in less egalitarian countries, and this change could be masked by the overall lack of change in the more egalitarian countries, or by changes in sample composition and other characteristics. To test this, we turn to country-level context and changes in housework patterns. Our approach to context was twofold. We were most interested in whether and how a country's 1994 housework patterns had an effect on domestic division of labor reports in 2002. We further examined to what extent this relationship remained stable once we took into account other sociopolitical indicators. We found a significant positive association between the aggregate household division of labor in 1994 and the division of labor in 2002. In line with existing research, respondents in countries with a more egalitarian division of labor in 1994 reported more egalitarian patterns in 2002, holding constant other couple-level predictors.

This positive significant relationship was attenuated, but persisted, even when a variety of other contextual factors were introduced. Our results indicated a significant positive relationship between more egalitarian housework reports and a country's female labor force participation and the absence of discriminatory policies. Living in a country with longer parental leave, on the other hand, was associated with less egalitarian housework arrangements, all else equal. Our results also suggested that the type of welfare state context affected the division of labor, net of individual characteristics and net of a division of labor patterns in previous years. Compared to those living in liberal welfare states, those who resided in conservative welfare states or Eastern European countries showed a more traditional division of labor, net of individual characteristics and their countries' previous housework patterns (Model 9 excluded observations from Norway, the lone social democratic country, as welfare state and country effect could not be separated. Supplemental analyses indicated no significant difference between Norway and liberal countries and excluding it does not substantively alter the findings).

Our results have established that country level housework standards and traditions mattered even when we took into account other socio-political country characteristics. In a final step we examined whether there was a curvilinear effect of country level housework patterns that supported the notion of convergence of housework patterns across countries as proposed by Hypothesis 2 (see Table 5). We chose the three models that showed the greatest reduction in between-country variation and re-estimated them allowing for a curvilinear effect of country level housework patterns. The results presented in Table 5 provided modest evidence for a curvilinear effect that is consistent with convergence. The addition of an additional covariate resulted in a slight worsening of the overall model fit, but we find a further reduction in the between country variation. Models with third order polynomials are not shown here, but the 
predictions derived from them were substantively identical although the model fit is further worsened.

To illustrate the results from Table 5 Figure 2 shows predicted values for the domestic division in 2002 of labor for a female respondent who worked full time, had a husband who worked full time, and was average on other characteristics We varied the 1994 country level housework context based on Model 5. As a contrast we also included a solid line (labeled "stability" to illustrate the housework predictions if the country level housework patterns of 1994 were to be simply replicated in 2002. The positive slope indicates that living in a country with a more traditional division of labor in 1994 was associated with reports of smaller male share of housework in 2002. The link between housework context and predicted housework patterns was curvilinear for all three models presented, but it was most pronounced when we also accounted for general welfares state context. For respondents in more traditional countries the male share of housework was well above the average 1994 levels, whereas for respondents in somewhat more egalitarian countries our models predicted housework scores are that much closer to the country averages in 1994, most consistent with a convergence pattern.

\section{Discussion}

In this paper we examined changes in domestic labor patterns in comparative perspective. We found variation across countries in the extent of change in housework patterns between 1994 and 2002. Most importantly, our results supported the thesis of cultural convergence in which more traditional countries move faster toward egalitarianism over time.

We found, first, limited support for our hypothesis (H1b) that individual characteristics become more important over time. The increased the gender gap in housework reporting may reflect growing social desirability effects, driving men's over-reporting of their housework contributions. Of course, the growing discrepancy may also reflect women's frustration with their housework burdens and declining likelihood to report equal sharing of housework tasks when equality is not fully met. The widening difference in housework between full time workers and those who are not suggests that perhaps, as women's labor force participation is becoming more normative, those who are not employed full time have a weakened bargaining position, which echoes findings by (Geist, 2009).

Second, our results provided strong evidence for path dependency in housework patterns. Countries' past division of labor patterns mattered net of individual characteristics in shaping individuals' housework reports. We interpret this as further evidence that context matters, perhaps by setting lasting national housework "standards." Our results suggested a curvilinear relationship between past housework context and the later couple division of labor, implying that the move towards egalitarianism was more pronounced in countries with a more traditional past division of labor than in countries that were already more egalitarian. One way of interpreting these results is that the path dependency in behavioral patterns was weaker in countries that are furthest away from the levels of equality towards which housework patterns converge.

We want to acknowledge some limitations to our study. Because of the relative nature of our housework measure, we cannot address questions of time spent on housework and overall trends in the housework burden. As such, our study addresses issues of justice and gender equality more so than issues of time use. We also exclusively focus on routine tasks, excluding those that may not be applicable to all couples, such as yard work or child care, or tasks that are done predominantly by men. Further research needs to examine whether there is cross-national convergence in parents' child care behavior and time spent on housework 
tasks by men and women. Also, we cannot exclude the possibility that some of our findings are driven by a regression to the mean or possible ceiling effects. Future studies need to verify our findings using longer time spans and a broader set of countries.

Our finding of cross-national convergence in the domestic division of labor further adds to the body of research on trends in gender equality in comparative perspective and the world culture literature. We found support for the idea of movement towards a world culture with greater gender equality. This optimistic outlook on the future of gender relations is tempered by the fact that the overall changes are modest in nature -- although our time window is admittedly narrow. Moreover, our results indicated that the convergence is towards greater gender equality, not necessarily completely equal sharing of domestic responsibilities. Even in the most egalitarian countries in our sample, women still were responsible for the majority of the housework. In that sense, both pessimistic and optimistic views on the future of gender equality may find support in our analysis.

\section{Acknowledgments}

This research was supported in part by the grant 5 T32 HD07168-30, awarded to the Carolina Population Center at The University of North Carolina at Chapel Hill by the Eunice Kennedy Shriver National Institute of Child Health and Human Development. We thank Makiko Fuwa for sharing her data and the editor and reviewers for their detailed suggestions.

\section{References}

Alwin DF, Braun M, Scott J. The separation of work and the family: Attitudes towards women's labour-force participation in Germany, Great Britain, and the United States. European Sociological Review. 1992; 8:13-37.

Batalova JA, Cohen PN. Premarital cohabitation and housework: Couples in cross-national perspective. Journal of Marriage and Family. 2002; 64:743-755.

Bianchi SM, Milkie MA, Sayer LC, Robinson JP. Is anyone doing the housework? Trends in the gender division of household labor. Social Forces. 2000; 79:191-228.

Boli J, Thomas GM. World culture in the world polity: a century of international non-governmental organization. American Sociological Review. 1997; 62:171-190.

Bolzendahl CI, Myers DJ. Feminist attitudes and support for gender equality: Opinion change in women and men, 1974-1998. Social Forces. 2004; 83:759-789.

Brines J. Economic dependency, gender, and the division of labor at home. American Journal of Sociology. 1994; 100:652-688.

Brooks C, Bolzendahl C. The transformation of US gender role attitudes: cohort replacement, socialstructural change, and ideological learning. Social Science Research. 2004; 33:106-133.

Chang ML. The evolution of sex segregation regimes. American Journal of Sociology. 2000; 105:1658-1701.

Coltrane S. Research on household labor: Modeling and measuring the social embeddedness of routine family work. Journal of Marriage and the Family. 2000; 62:1208-1233.

Coltrane S, Ishii-Kuntz M. Men's housework: A life course perspective. Journal of Marriage and the Family. 1992; 54:43-57.

Cooke LP, Baxter J. "Families" in international context: Comparing institutional effects across western societies. Journal of Marriage and Family. 2010; 72:516-536.

Cunningham M. Gender in cohabitation and marriage: The influence of gender ideology on housework allocation over the life course. Journal of Family Issues. 2005; 26:1037-1061.

Davis S, Greenstein T, Gerteisen Marks J. Effects of union type on division of household labor. Journal of Family Issues. 2007; 28:1246.

Davis SN, Greenstein TN. Cross-national variations in the division of household labor. Journal of Marriage and Family. 2004; 66:1260-1271. 
De Ruijter E, Treas JK, Cohen PN. Outsourcing the gender factory: Living arrangements and service expenditures on female and male tasks. Social Forces. 2005; 84:305.

Esping-Anderson, G. The three worlds of welfare capitalism. Princeton: Princeton University Press; 1990.

Esping-Anderson, G. Social foundations of post-industrial society. Oxford: Oxford University Press; 1999.

Fuwa M. Macro-level gender inequality and the division of household labor in 22 countries. American Sociological Review. 2004; 69:751-767.

Fuwa M, Cohen PN. Housework and social policy. Social Science Research. 2007; 36:512-530.

Ganzeboom HBG, Treiman DJ, Ultee WC. Comparative intergenerational stratification research - 3 generations and beyond. Annual Review of Sociology. 1991; 17:277-302.

Geist $\mathrm{C}$. The welfare state and the home: Regime differences in the domestic division of labour. European Sociological Review. 2005; 21:23-41.

Geist C. One Germany, two worlds of housework? Examining employed single and partnered women in the decade after unification. Journal of Comparative Family Studies. 2009; 40:415-437. [PubMed: 20582232]

Geist, C. Gendered views of domestic labor: Cross-National variation in men's and women's' reports of housework. In: Treas, J.; Drobnič, S., editors. Dividing the domestic: Women, men and housework in cross-national perspective. Stanford: Stanford University Press; 2010.

Gershuny, J. Changing times: Work and leisure in postindustrial society. Oxford: Oxford University Press; 2000.

Gesthuizen, M.; Solga, H.; Künster, R. European Sociological Review. Context matters: Economic marginalization of low-educated workers in cross-national perspective. (Forthcoming)

Goode, WJ. World revolution and family patterns. New York: Free Press of Glencoe; 1963.

Gubernskaya Z. Changing attitudes toward marriage and children in six countries. Sociological Perspectives. 2010; 53:179-200.

Hook J. Gender inequality in the welfare state: task segregation in housework, 1965-2003. American Journal of Sociology. 2010; 115:1480-1523.

Hook JL. Care in context: Men's unpaid work in 20 countries, 1965-2003. American Sociological Review. 2006; 71:639-660.

Inglehart, R.; Norris, P. Rising tide: Gender equality and cultural change around the world. Cambridge: Cambridge Univ Press; 2003.

International Social Survey Programme, I. FAMILY AND CHANGING GENDER ROLES II. Cologne, Germany: Zentralarchiv fur Empirische Sozialforschung; 1994.

International Social Survey Programme, I. FAMILY AND CHANGING GENDER ROLES III. Cologne, Germany: Zentralarchiv fur Empirische Sozialforschung; 2002.

Jackson, RM. Destined for equality: The inevitable rise of women's status. Cambridge, Mass: Harvard University Press; 1998.

Knudsen K, Waerness K. National context and spouses housework in 34 countries. European Sociological Review. 2008; 24:97-113.

Krook ML. Quota laws for women in politics: Implications for feminist practice. Social Politics. 2008; $15: 345-368$.

Lesthaeghe R. A century of demographic and cultural change in Western Europe: An exploration of underlying dimensions. Population and Development Review. 1983; 9:411-435.

Lesthaeghe R. The unfolding story of the second demographic transition. Population and Development Review. 2010; 36:211-251. [PubMed: 20734551]

Lohmann H. Welfare states, labour market institutions and the working poor: A comparative analysis of 20 European countries. European Sociological Review. 2009; 25:489-504.

McAdam D, Rucht D. The cross-national diffusion of movement ideas. Annals of the American Academy of Political and Social Science. 1993; 528:56-74.

Meyer OW, Boli J, Thomas GM, Ramirez FO. World society and the nation state. The American Journal of Sociology. 1997; 103:144-181. 
Mies, M. Patriarchy and accumulation on a world scale : Women in the international division of labour. London: Zed; 1998.

Moghadam VM. Transnational feminist networks: Collective action in an era of globalization. International Sociology. 2000; 15:57-85.

Muller EN. Democracy, economic development, and income inequality. American Sociological Review. 1988; 53:50-68.

Ruppanner L. Fairness and housework: A cross-national comparison. Journal of Comparative Family Studies. 2008; 39:509-526.

Schooler C. Cultural and social-structural explanations of cross-national psychological differences. Annual Review of Sociology. 1996; 22:323-349.

Smith TW. The International Social Survey Program. International Journal of Public Opinion Research. 1992; 4:275-278.

Sorensen A, McLanahan S. Married women's economic dependency. American Journal of Sociology. 1987; 93:659-687.

South SJ, Spitze G. Housework in marital and nonmarital households. American Sociological Review. 1994; 59:327-347.

Stier H, Lewin-Epstein N. Policy effects on the division of housework. Journal of Comparative Policy Analysis: Research and Practice. 2007; 9:235-259.

Thornton, A. Reading history sideways: The fallacy and enduring impact of the developmental paradigm on family life. Chicago: University of Chicago Press; 2005.

Treas, J.; Drobnic, S. Men, women, and household work in cross-national perspective. Standford: Stanford University Press; 2010.

True J, Mintrom M. Transnational networks and policy diffusion: The case of gender mainstreaming. International Studies Quarterly. 2001; 45:27-57.

West C, Zimmerman DH. Doing gender. Gender \& Society. 1987; 1:125-151.

Yodanis C. Divorce culture and marital gender equality. Gender \& Society. 2005; 19:644-659. 


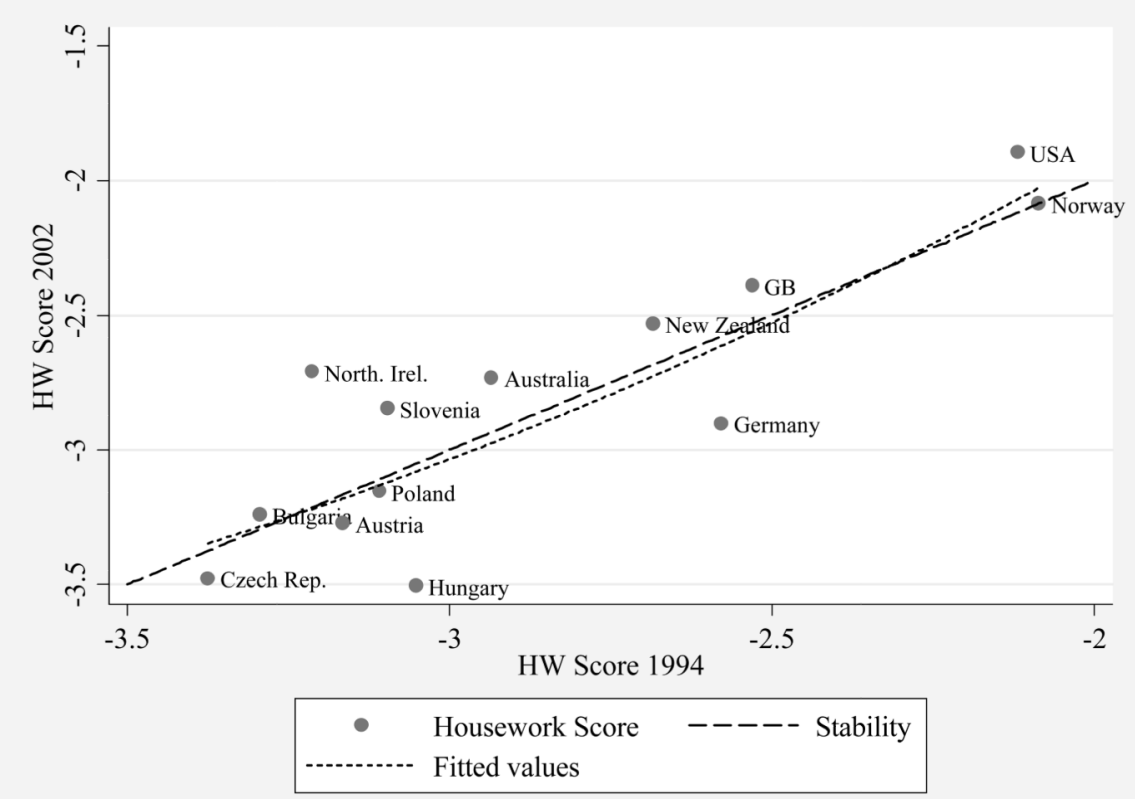

Figure 1.

Domestic Division of Labor 1994 and 2002 (Country Averages) 


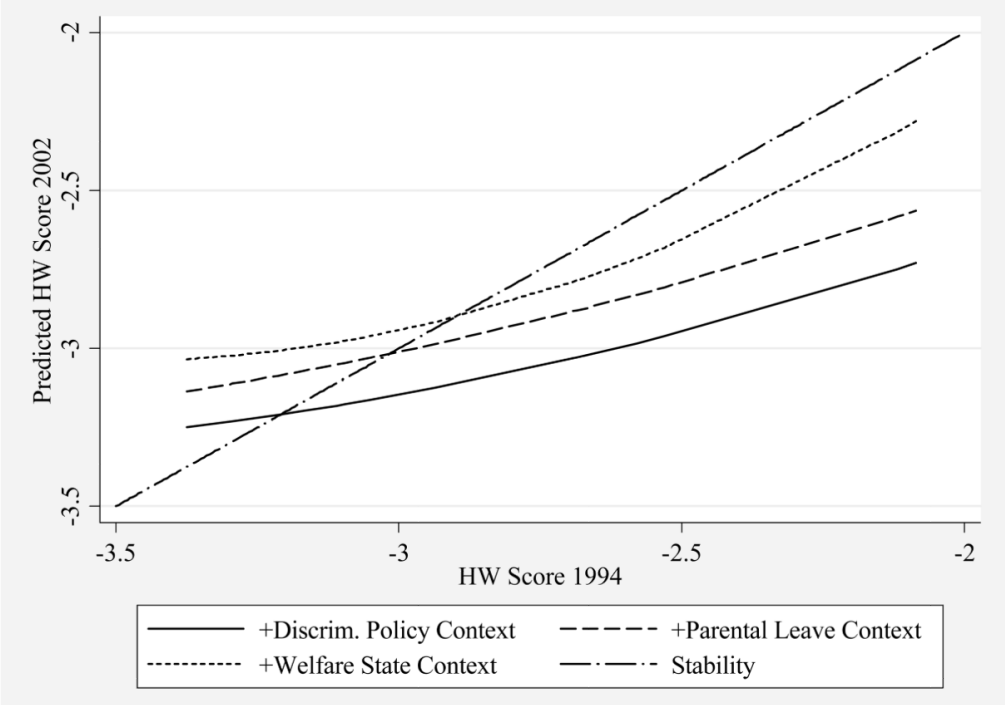

Figure 2.

Predicted Values for Domestic Division of Labor in 2002, by 1994 Housework Scores 
Table 1

Countries and Sample Sizes

\begin{tabular}{|c|c|c|c|}
\hline & Total & 1994 & 2002 \\
\hline Australia & 986 & 524 & 462 \\
\hline Austria & 766 & 260 & 506 \\
\hline Bulgaria & 630 & 353 & 277 \\
\hline Czech Republic & 692 & 328 & 364 \\
\hline Germany $^{a}$ & 1,425 & 1,005 & 420 \\
\hline Great Britain & 864 & 249 & 615 \\
\hline Hungary & 844 & 539 & 305 \\
\hline New Zealand & 780 & 418 & 362 \\
\hline Northern Ireland & 347 & 164 & 183 \\
\hline Norway & 1,493 & 876 & 617 \\
\hline Poland & 903 & 449 & 454 \\
\hline Slovenia & 591 & 343 & 248 \\
\hline USA & 744 & 372 & 372 \\
\hline Total & 11,065 & 5,880 & 5,185 \\
\hline
\end{tabular}

Note:

${ }^{a}$ Data for Germany was collected in 2 samples in 1994 (East and West Germany), but is treated as one country in both years. 
Table 2

\section{Descriptive Statistics}

\begin{tabular}{|c|c|c|c|c|}
\hline & Mean & Std. Dev & Min. & Max \\
\hline Housework score & -2.77 & 2.01 & -6 & 6 \\
\hline Female $(0=$ male, $1=$ female $)$ & 0.52 & - & 0 & 1 \\
\hline Age (in years) & 40.53 & 8.26 & 25 & 55 \\
\hline Married $(0=$ not married, $1=$ married $)$ & 0.93 & & 0 & 1 \\
\hline Household size & 3.49 & 1.04 & 2 & 5 \\
\hline Husband works full-time $(0=$ not full-time, $1=$ full-time $)$ & 0.86 & - & 0 & 1 \\
\hline Husband works part-time $(0=$ not part-time, $1=$ part-time $)$ & 0.02 & - & 0 & 1 \\
\hline Husband not employed $(0=$ employed, $1=$ not employed $)$ & 0.12 & - & 0 & 1 \\
\hline Wife works full-time $(0=$ not full-time, $1=$ full-time $)$ & 0.56 & - & 0 & 1 \\
\hline Wife works part-time $(0=$ not part-time, $1=$ part-time $)$ & 0.15 & - & 0 & 1 \\
\hline Wife not employed $(0=$ employed, $1=$ not employed $)$ & 0.29 & - & 0 & 1 \\
\hline Gender Role Attitude & 9.24 & 3.11 & 3 & 15 \\
\hline College/university education $(0=$ no college, $1=$ college education $)$ & 0.30 & - & 0 & 1 \\
\hline Men's share of HH income & 0.64 & - & 0 & 1 \\
\hline \multicolumn{5}{|l|}{ Macro Level Indicators } \\
\hline Female Labor Force Participation & 65.55 & 6.45 & 52.3 & 77.2 \\
\hline Female to Make Earnings Ratio & 0.61 & 0.10 & 0.4 & 0.7 \\
\hline Separate Roles Attitudes & 3.47 & 1.26 & 1.0 & 5.0 \\
\hline Cohabitation Rate & 6.65 & 2.76 & 1.3 & 10.7 \\
\hline Absence of Discriminatory Policies & 2.07 & 0.93 & 1.0 & 3.0 \\
\hline Parental Leave (in weeks) & 20.62 & 12.80 & 2.8 & 36.0 \\
\hline Public Childcare Availability Score & 69.58 & 15.99 & 36.7 & 90.5 \\
\hline
\end{tabular}

Note: $N=11065$ respondents. 
Table 3

Random Intercept Regression of Housework Score on Individual Characteristics, 1994 and 2002.

\begin{tabular}{|c|c|c|c|c|}
\hline & \multirow[b]{2}{*}{ (1) } & \multirow[b]{2}{*}{ (2) } & \multicolumn{2}{|c|}{ (3) } \\
\hline & & & Main Effects & Interaction \\
\hline Survey Year 2002 & $0.001(0.04)$ & $-0.06(0.04)$ & $-1.24(0.90)$ & \\
\hline Female & & $-0.72^{* * *}(0.04)$ & $-0.61^{* * *}(0.05)$ & $-0.22^{* *}(0.07)$ \\
\hline Husband working PT & & $0.81^{* * *}(0.13)$ & $0.57^{* *}(0.20)$ & $0.38(0.26)$ \\
\hline Husband not employed & & $0.49^{* * *}(0.06)$ & $0.48^{* * *}(0.09)$ & $0.02(0.12)$ \\
\hline Wife working PT & & $-0.39^{* * *}(0.06)$ & $-0.30^{* * *}(0.08)$ & $-0.21+(0.11)$ \\
\hline Wife not employed & & $-0.54^{* * *}(0.05)$ & $-0.45^{* * *}(0.07)$ & $-0.18+(0.09)$ \\
\hline Husband's share of HH income & & $-0.42^{* * *}(0.08)$ & $-0.55^{* * *}(0.13)$ & $0.20(0.17)$ \\
\hline Married & & $-0.30^{* * *}(0.08)$ & $-0.14(0.14)$ & $-0.26(0.17)$ \\
\hline Age & & $0.004(0.02)$ & $-0.03(0.03)$ & $0.07(0.05)$ \\
\hline Gender attitudes & & $0.09^{* * *}(0.01)$ & $0.09^{* * *}(0.01)$ & $<-0.001(0.01)$ \\
\hline College degree & & $0.31^{* * *}(0.04)$ & $0.31^{* * *}(0.06)$ & $0.002(0.08)$ \\
\hline Household size & & $-0.17^{* * *}(0.02)$ & $-0.18^{* * *}(0.03)$ & $0.02(0.04)$ \\
\hline Intercept & $-2.84^{* * *}(0.13)$ & $-1.58^{* * *}(0.45)$ & $-1.09+(0.61)$ & \\
\hline Standard Deviation of intercept & $0.45^{* * *}(0.09)$ & $0.33^{* * *}(0.07)$ & $0.27^{* * *}(0.07)$ & \\
\hline Random Slope of "Year" (Covariance) & & & $0.32^{* * *}(0.07)$ & \\
\hline Residual Standard Deviation & $1.96^{* * *}(0.01)$ & $1.85^{* * *}(0.01)$ & $1.85^{* * *}(0.01)$ & \\
\hline BIC & 46411 & 45297 & 45419 & \\
\hline
\end{tabular}

Note: $N=11065$. Numbers in parentheses are standard errors. Models also include a squared term for age as a control.

$*$

$p<.05$

$* *$

$p<.01$

*** $p<.001$ 


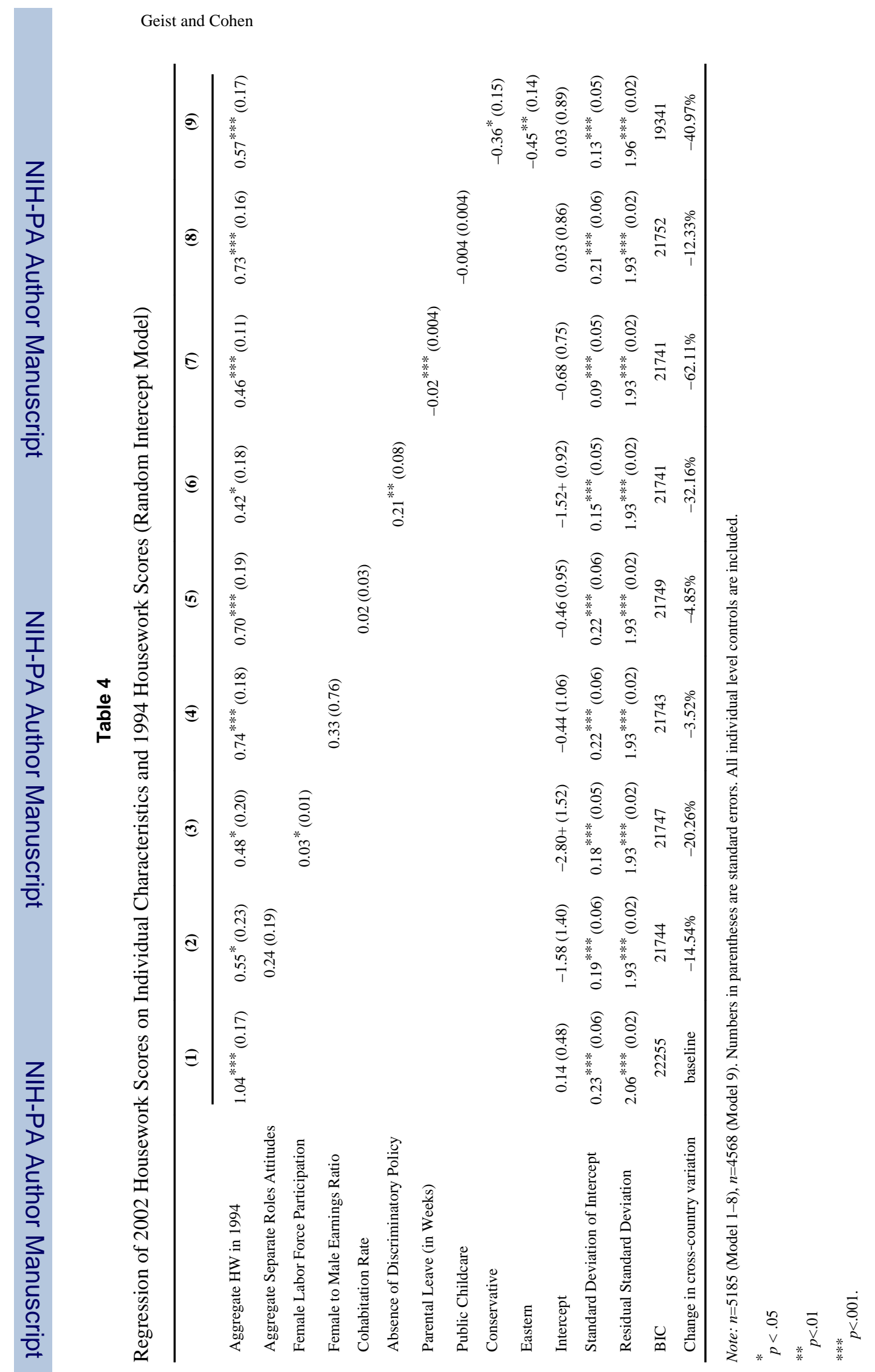

J Marriage Fam. Author manuscript; available in PMC 2014 January 22. 

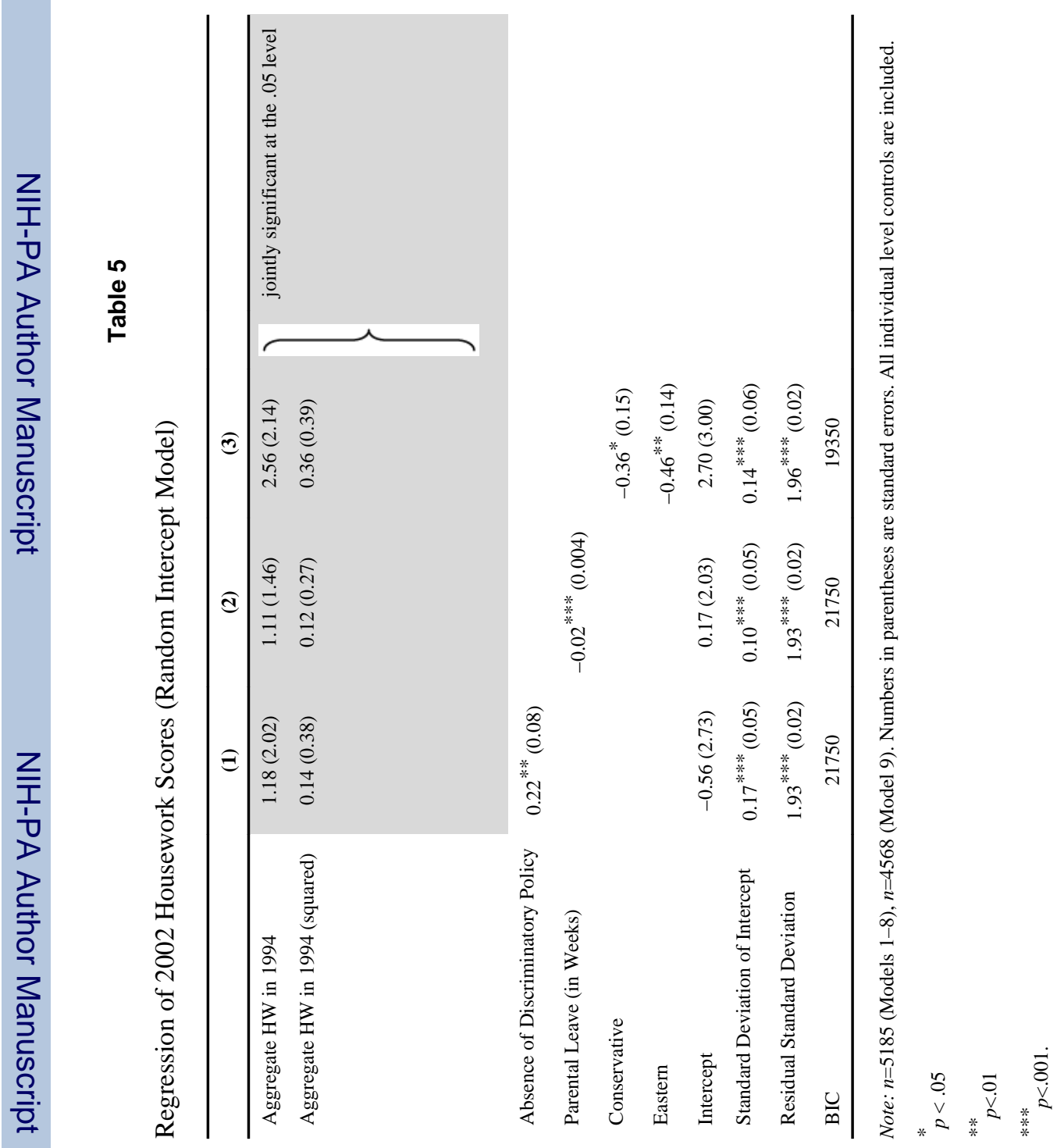

J Marriage Fam. Author manuscript; available in PMC 2014 January 22. 